\title{
Boronic acids for sensing and other applications - a mini-review of papers published in 2013
}

Karel Lacina ${ }^{1,2}$, Petr Skládal ${ }^{1,3}$ and Tony D James ${ }^{2^{*}}$

\begin{abstract}
Boronic acids are increasingly utilised in diverse areas of research. Including the interactions of boronic acids with diols and strong Lewis bases as fluoride or cyanide anions, which leads to their utility in various sensing applications. The sensing applications can be homogeneous assays or heterogeneous detection. Detection can be at the interface of the sensing material or within the bulk sample. Furthermore, the key interaction of boronic acids with diols allows utilisation in various areas ranging from biological labelling, protein manipulation and modification, separation and the development of therapeutics. All the above uses and applications are covered by this mini-review of papers published during 2013.
\end{abstract}

Keywords: Boronic acid, Sensing, Detection of glucose, Diol, Catechol, Fluoride, Reactive oxygen species

\section{Introduction}

The following article is a mini review on boronic acids for sensing and other applications for papers published in 2013. It is important to note that the review does not cover any synthetic applications of boronic acids for publications on these areas you are directed to some excellent recent reviews [1-3]. This text does however cover the diverse range of uses and applications for boronic acids from therapeutics to separation technologies (Figure 1).

During 2013 the established area of synthetic receptors for low molecular compounds was further developed, in particular some novel detection methodologies were introduced. However, an area of particular growth was the interaction of boronic acids with proteins, their manipulation and cell labelling. Boronic acid were also used for electrophoresis of glycated molecules. They were also employed as building materials for microparticles for analytical methods and in polymers for the controlled release of insulin.

\section{Reviews}

Boronic acid molecules as the building block for a diverse range of sensing systems has been the central theme for

\footnotetext{
* Correspondence: t.d.james@bath.ac.uk

${ }^{2}$ Department of Chemistry, University of Bath, Claverton Down, Bath BA2 7AY, UK

Full list of author information is available at the end of the article
}

several review papers during the course of the 2013. A general review on all aspects of boronic acid interactions with cis-diols and sensing applications [4] and a summary of sensing with multivalent boronic acid sensor molecules discussing methods to improve selectivity towards specific analytes [5] were published. Other reviews dealt with the use of boronic acids as biochemical tools for various purposes, including the interference in signalling pathways, enzyme inhibition and cell delivery systems [6]. While an overview of organoborons [7] and boronic acid-functionalised materials [8], demonstrates their crucial role in carbohydrate chemistry and glycobiology, especially the areas of analysis, separation, protection, and activation.

Boronic acid-containing hydrogels are important intelligent materials. The introduction of boronic acid functionality to these hydrogels allows them to exhibit many interesting properties, such as glucose-selectivity/ sensitivity, reversible binding and self-healing ability. The application with an emphasis on biomedical areas i.e. the design of various glucose sensors and self-regulated insulin delivery devices have been described in detail [9].

However, pure sensing applications represent the major impetus of boronic acid research. Reviews summarising fluorescence $[10,11]$ and electrochemically active derivatives of boronic acid [12] have been compiled. Boronic acid sensors with practical applications were part of a review on subcutaneous in vivo glucose monitoring [13,14]. 


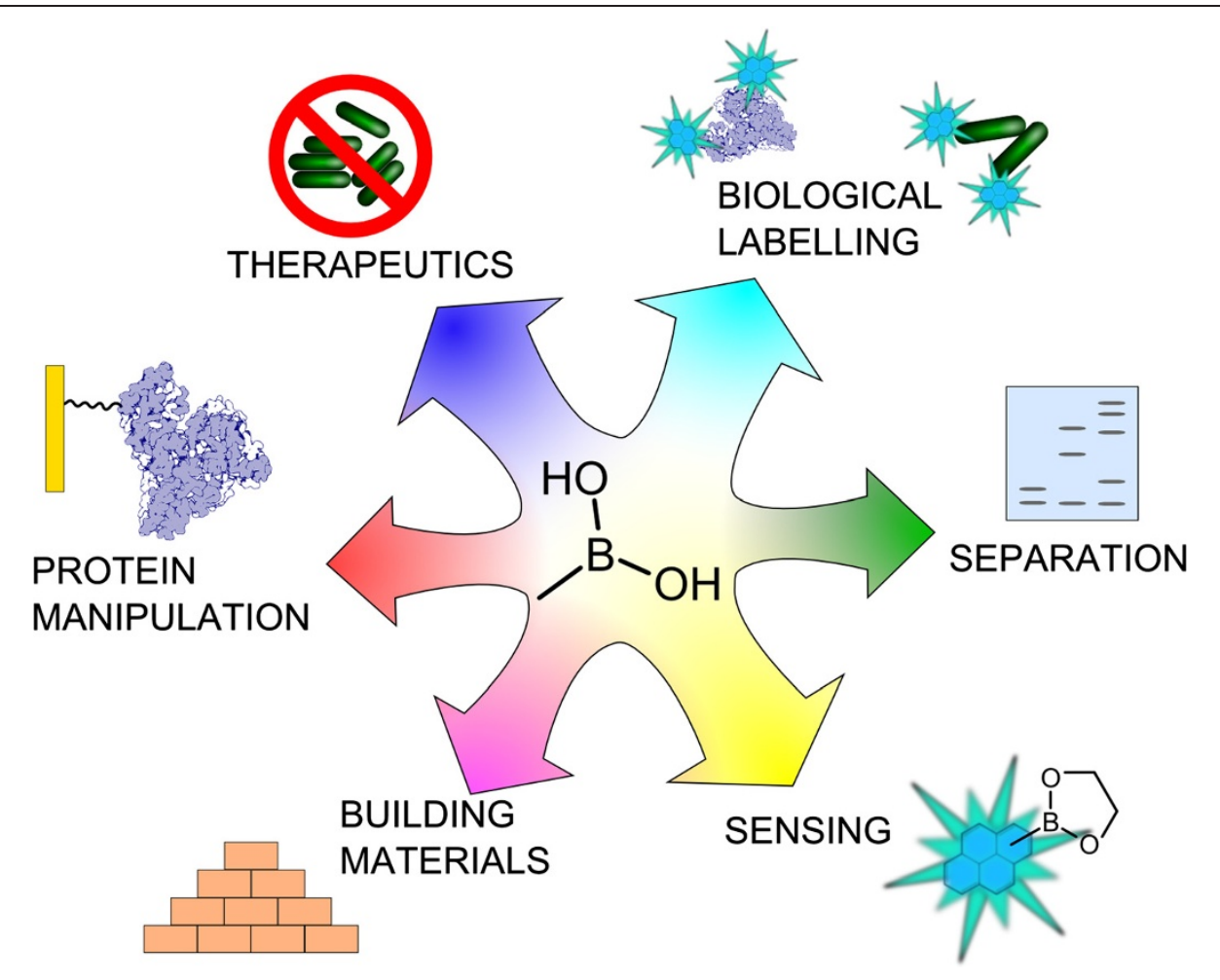

Figure 1 Diverse usage and applications of boronic acids.

\section{Sensing in homogeneous phase with synthetic receptors}

The most common sensing format is the homogeneous assay (Figure 2). Two interacting partners analyte and the molecular sensor are present in solution. The sensor molecules containing a boronic acid and reporting unit are prepared to match the sensing application and analytical environment. Interactions between the analyte and the sensor result in the change in the physico-chemical properties of the reporter.

\section{Carbohydrates}

The most pursued molecular sensor based on boronic acid is a sensor for monosaccharides and in particular glucose. Several reports dealing with the synthesis and characterisation of novel fluorescent recognition systems with new mechanisms are being actively pursued. For example pyrene-based boronic acids were shown to bind glucose [15] and monosaccharides [16].

The well-known and elegant Alizarin Red S (ARS) phenylboronic acid displacement assay developed by

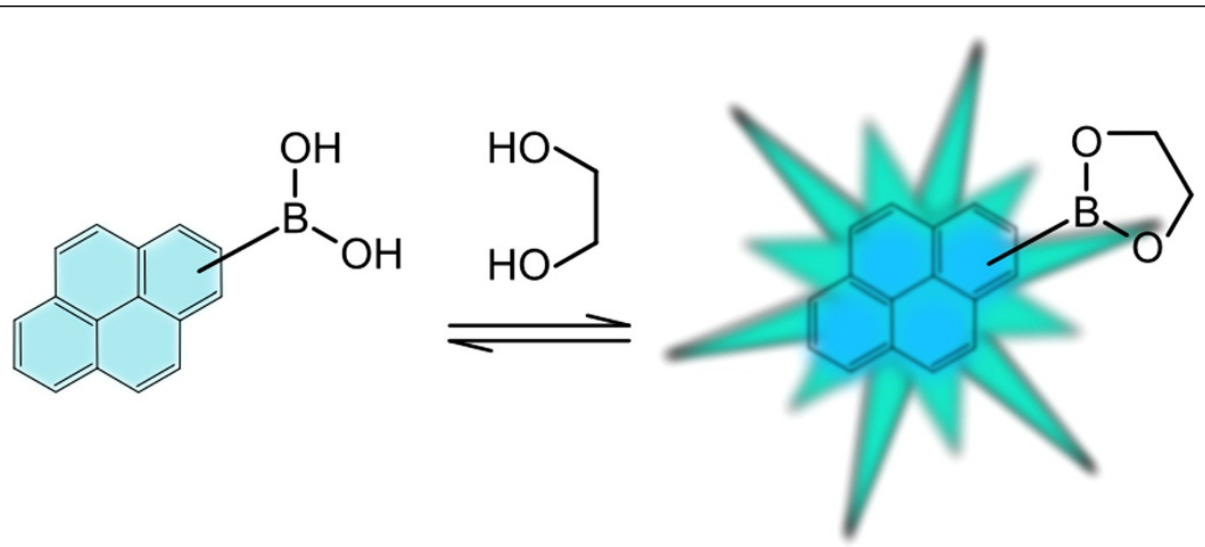

Figure 2 Boronic acid-based molecular sensors for homogeneous optical detection of diols. 
Binghe Wang [17] was adapted using a fluorescent dye and a quencher - boronic acid appended viologen. The quenched fluorescence of the dye was recovered upon boronic acid-glucose interaction [18].

The problem associated with the higher affinity of boronic acids towards D-fructose over D-glucose was addressed in the elegant work by James and Jiang (Figure 3). Higher specificity of boronic acid towards glucose was achieved using the stoichiometry of "glucose" and "fructose" binding. The pyrene-boronic acid derivative produced amorphous 1:1 conjugates in the presence of D-fructose. While highly ordered and fluorescent 2:1 conjugates were obtained in the presence of D-glucose. With this system both boronic acid-diol interactions and the $\pi$-stacking and aggregation of pyrene units were involved in the selectivity of the sensing mechanism. Moreover D-fructose in a mixture of D-fructose and D-glucose could be "knocked-out" by adding phenylboronic acid since it interacts strongly (selectively binds) with D-fructose [19].

An interesting molecule with great potential, is boronic acid modified bullvalene and its ability to isomerise into different shapes was utilised for polyol detection (Figure 4). The labile structure of the sensor molecule could be frozen by addition of polyol and the changes followed by ${ }^{13} \mathrm{C}$ NMR. The NMR spectrum was used to develop a "finger-print" barcode. The sensor molecule could be considered as a self-contained sensor array. The interaction with ten diverse polyols in DMSO/phosphate buffer was investigated. Mixtures of polyols could be analysed with this sensor molecule and the strongest binding analyte dominated the corresponding read-out. It was proposed that NMR can be used as a noninvasive technique for in vivo sensing [20].

Many fluorogenic units are used for reporting the interactions of diols with boronic acids. The fluorophores used include pyrene $[15,16,19]$, coumarin [21], naphthalene [22] and BODIPY [23]. Furthermore multi-colorimetric sensor arrays were developed using boronic acid-containing thin films combined with three anionic dyes for saccharide detection. The binding of saccharides was monitored via changes of colour [24].

A boronic acid-based sensor system was used for the detection and labelling of bacteria [22]. A change in $\mathrm{pH}$ caused by the boronic acid-fructose interaction was followed during the fermentation process. The $\mathrm{pH}$ dependent change of colour by the indicator rhodamine $\mathrm{B}$ resulted in a measurable signal "out-put" [25].

Boronic acid - carbohydrate interactions were also employed for the fluorescence visualisation of tumours. Sensor system prepared using a peptide connected with two boronic acid groups (anthracene based sensors [4]) exhibited high specificity towards sialyl Lewis $\mathrm{X}$ and was used for the selective labelling of cell-surface glycans of human hepatic cancer cells [26]. Over-expressed carbohydratebased carcinoma biomarker, sialyl Lewis X was selectively labelled in the mouse xenograft tumour via this novel boronolectin-fluorophore (Figure 5) [27].

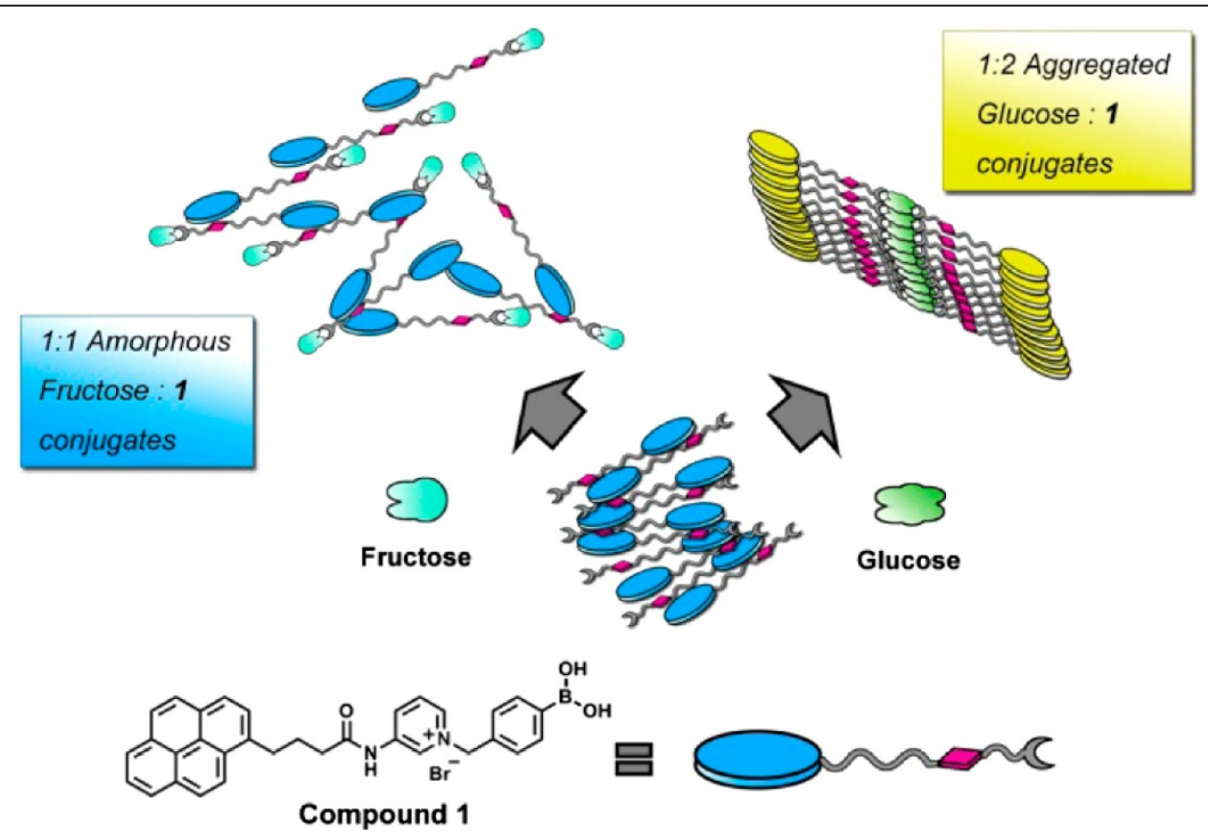

Figure 3 Molecular sensor forms amorphous conjugates in the presence of D-fructose. Highly structured and fluorescent conjugates are formed in the presence of D-glucose. (Adapted from ref. [19]). 


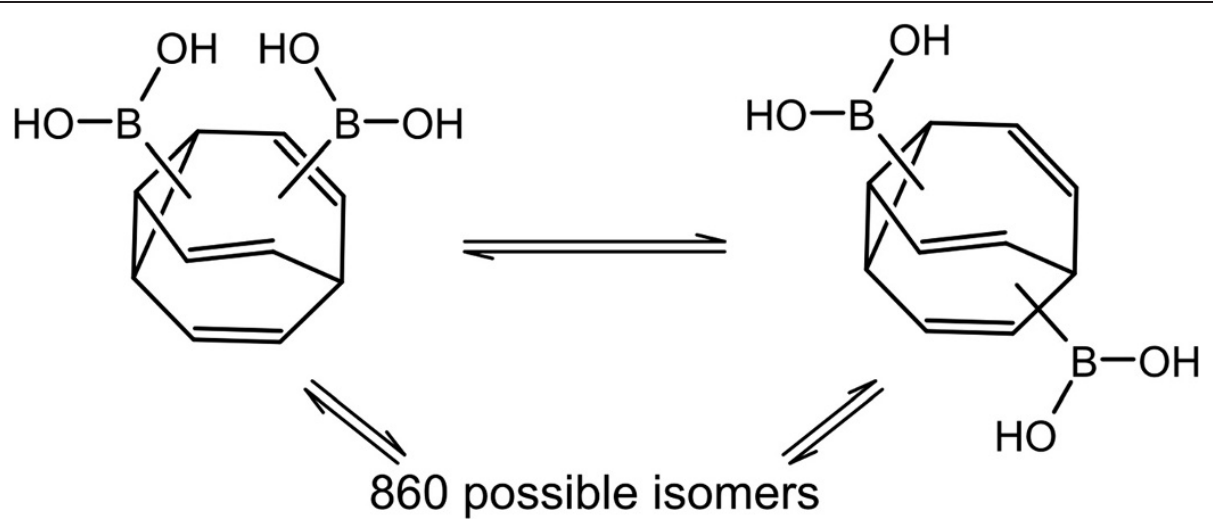

Figure 4 Boronic acid appended bullvalene can form a multitude of isomers allowing construction of a self-contained sensor array [20].

\section{Catechol derivatives}

Aromatic cis-diols/catechol derivatives are another group of compounds that strongly bind to boronic acid receptors. A detection system based on the FRET between two separate fluorophore containing receptor units permitted the selective detection of catecholamine derivatives (Figure 6). In the presence of the catechol analyte the two sensor molecules - boronic acid and aldehyde are brought into close proximity and FRET was observed [28].
Another fluorescent sensor combining boronic acid and pyrene was studied and used as a sensor for catechol and its amino-derivatives - dopamine, DOPA and DOPAC. Interestingly D-fructose, D-glucose and phenylalanine did not affect the fluorescence. Theoretical calculations were carried out on the boronate esters and the fluorescence signalling was discussed [29]. A similar set of analytes, namely noradrenaline, dopamine, DOPA and catechol were also investigated using phenylboronic acid and its aminophosphonate analogue (1) (Figure 7) [30]. No significant
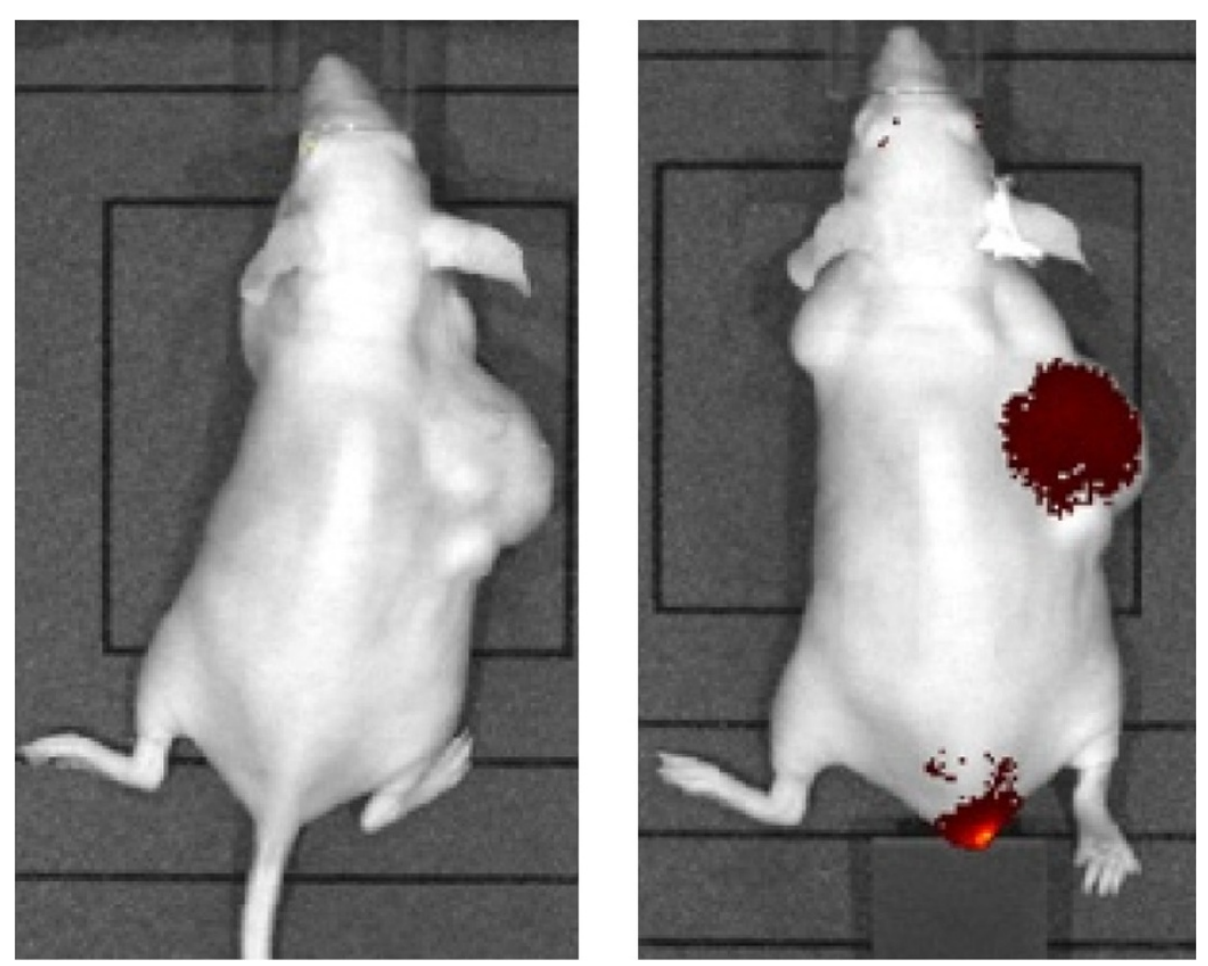

Figure 5 Optical imaging of xenograft tumour by specific boronolectin-fluorophore, left: mouse before imaging agent injection; right: mouse $24 \mathrm{~h}$ after tail vein injection of the contrast agent showing almost exclusive delivery to the tumour site. (Adapted from ref. [27]). 


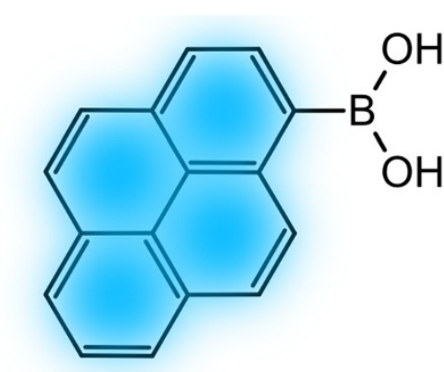<smiles>CCN(CC)c1ccc2cc(C=O)c(=O)oc2c1</smiles><smiles>NCCc1ccc(O)c(O)c1</smiles><smiles>C=Cc1ccc(B2Oc3ccc(CCN=Cc4cc5ccc(N(CC)CC)cc5oc4=O)cc3O2)c(C=C)c1C</smiles>

Figure 6 Schematic visualisation of the detection system for catecholamine derivatives combining boronic acid-diol, aldehyde-amine interactions and the FRET process [28].<smiles>OB(O)c1cccc(C(NCc2ccccc2)P(O)O)c1</smiles><smiles>O=C(CCCCC1CCSS1)NCCCCCCN(CCCCCCN(Cc1ccccc1B(O)O)Cc1ccccc1B(O)O)Cc1ccc2ccc3cccc4ccc1c2c34</smiles>

Figure 7 Structures of selected boronic acid derivatives.<smiles>OB(O)c1cc[n+](Cc2ccc3ccc4cccc5ccc2c3c45)cc1</smiles>

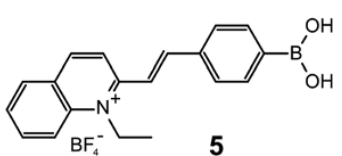


difference in the selectivity across the tested range of the analytes was observed.

\section{Fluoride or other anions}

The inherent chemical nature of boronic acid as a Lewis acid provides further possibilities to detect strong Lewis bases such as fluoride anions. A fluoride sensor combining boronic acid and fluorogenic naphthoimidazolium (2) was reported [31]. A pyrene based molecular sensor (3) was also developed for the detection of fluoride using a biphasic (organic solvent/water) system. Environmentally important levels of fluoride found in drinking water could be determined with this system [32]. An ensemble for the detection of anions was constructed from fluorescent pyrene-based polyelectrolyte with pyridine boronic acid acting as the quencher. The quenched fluorescence of the fluorescent polyelectrolyte was recovered after binding of fluoride or cyanide to the boronic acid [33].

The cyanide concentration could be quantified using a sensor constructed from phenylboronic acid and methylpyridinium [34]. Amygdalin could be detected by using the enzyme beta-glucosidase and a boronic acid appended viologen - quencher and pyrene-based fluorescent reporter dye (Figure 8). Enzyme cleavage of the amygdalin releases glucose, benzaldehyde and cyanide anion. The generated cyanide anion reduces quenching by the boronic acid quencher and the fluorescence signal is enhanced (recovered) [35].

\section{Simple surfaces modifications for sensing applications}

Advantageous sensing modality is achieved by the attachment of sensor molecules to a surface (Figure 9). The sensing format is then heterogeneous since the binding and detection event take place at the liquid/solid interface. Such systems are desirable since they are suitable for "real" analytical applications.

Although fluorescence is more often used for homogeneous systems it can also be used for heterogeneous systems. A fluorescence sensor prepared by the immobilisation of 4-mercaptophenylboronic acid on to a gold CDtrode (compact disc) was used to determine the concentration of monosaccharides down to picomolar levels [36]. However, other signal transduction mechanisms are often used for the read-out from surface sensors. A sensor for hemagglutinin a possible bio-marker for influenza A virus was developed using quartz crystal microbalance (QCM) and surface plasmon resonance (SPR) transducers. The surface of a sensor was modified with aminophenylboronic acid. The boronic acid was then used to anchor sialic acid to the surface, thus, creating a hemagglutinin selective surface [37]. A D-glucose selective SPR sensor (4) [38] was developed using a glucose selective bis-boronic acid unit [39] with thiolic functionality, allowing simple attachment to a gold surface. A simple boronic acid was also used for a surface-enhanced Raman scattering (SERS) monosaccharide assay (Figure 10). The boronic acid served both as capturing agent and the triosmium carbonyl boronic acid was employed as a secondary label (in a sandwich assay) [40].

Electrochemical sensing methods are highly advantageous for the transduction of surface confined boronic acid-diol binding events. For instance, the electrochemical impedance of a boronic acid derivatised electrode surface responded to the presence of glucose [41] and other monosaccharides [42] as well as glycated haemoglobin [43].

Modulation of the volt-ampere characteristics of a field effect transistor (FET) due to charge accumulation i.e. analyte binding was also utilised. Electrolyte-gated

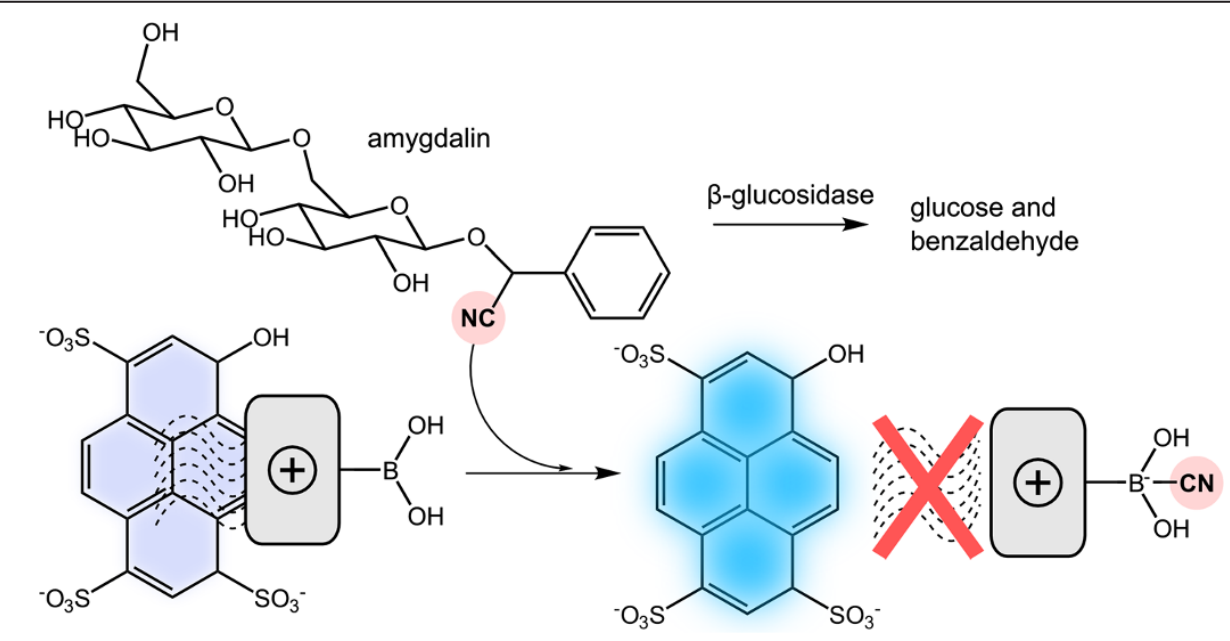

Figure 8 Fluorescence of a pyrene-based reporter is quenched by uncomplexed boronic acid. The enzymatically cleaved cyanide group from amygdalin binds to the boronic acid and quenching of the reporter dye is reduced [35]. 


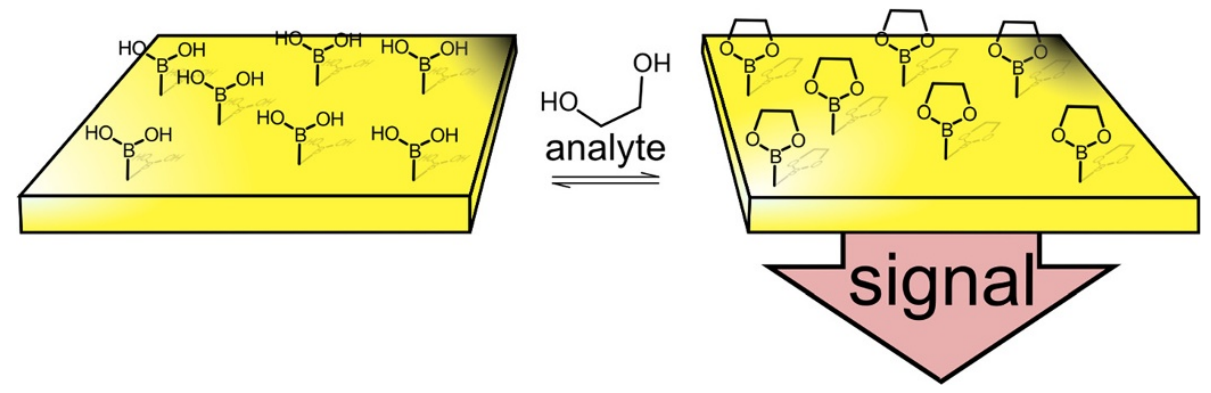

Figure $9 \mathrm{~A}$ heterogeneous detection of diols by means of boronic acid-based sensors assembled in monolayers on a simple surface.

organic FET with input modified by a derivative of phenylboronic acid was used to detect the binding of dopamine [44]. Release of the same analyte was quantified by a silicon nanowire FET after stimulation of PC12 cells by the addition of $\mathrm{K}^{+}$ions [45]. A so-called bio-FET produced using a fluorinated derivative of phenylboronic acid was proposed as a suitable glucose sensor for developing countries since it is simple, cheap and a protein-free analytical device [46].

Polymeric and other supports for sensing applications A significant enhancement of binding and hence the performance of a sensor system can be achieved by incorporation of a boronic acid unit into a polymer matrix
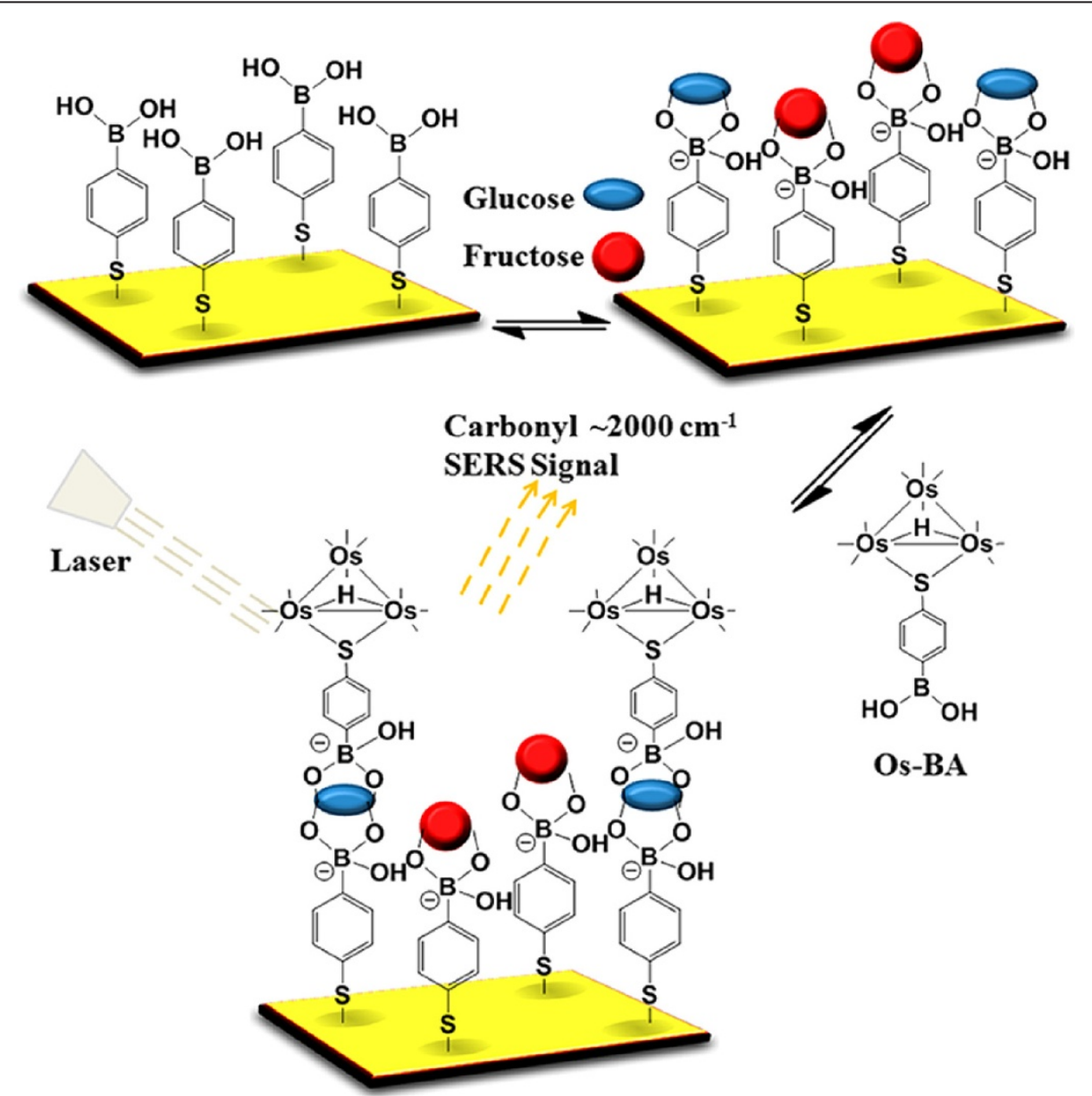

Figure 10 Surface enhanced Raman scattering sensors for monosaccharides based on boronic acids. The selectivity for glucose is achieved using 2:1 sandwich-like binding. (Adapted from ref. [40]). 

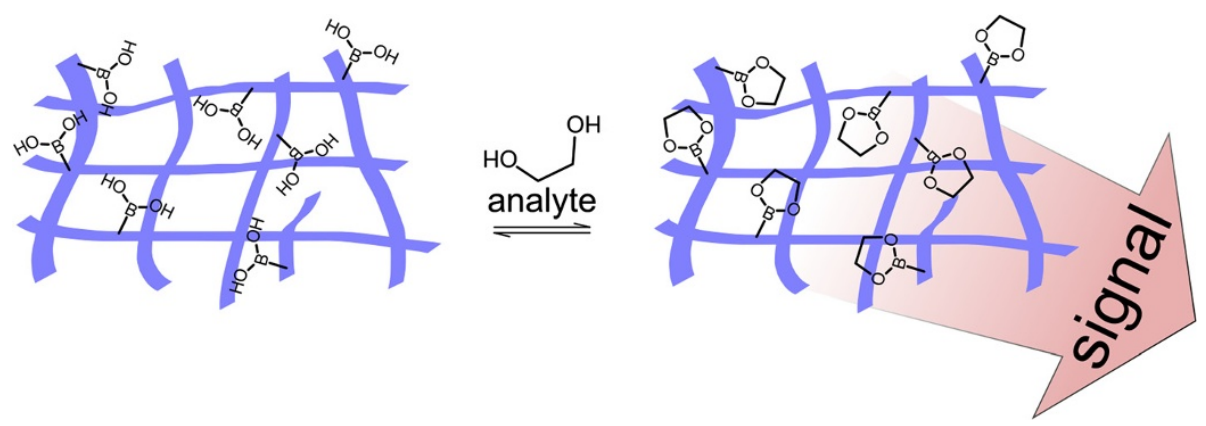

Figure 11 Detection of diols using boronic acid appended polymer matrix.

(Figure 11, Table 1). The inclusion of the molecular sensor into the polymer can help in the development of superior analytical devices, since the polymer imparts many advantages such as improved robustness, sensitivity, handling and biocompatibility. The properties are vital for the development of non-invasive D-glucose sensors [47]. Photonic crystals consisting of a copolymer of acryl amide and styrene gel scaffold with tethered boronic acid was developed to be used for the determination of glucose in tears in the form of contact lenses. Analytical information is obtained from changes of reflected near-infrared light. Photonic crystal can be fabricated via self-assembly. A lamellar block polystyrene scaffold with phenylboronic acid was prepared and its behaviour in the presence of fructose was investigated, a visible colour change from blue to orange was observed [48].

Sensing of oxygen and glucose was performed under biological conditions. A sensor consisting of a polyacrylamidebased matrix with three different fluorescent probes for oxygen, glucose and one reference channel was used to detect the consumption of glucose and oxygen by bacterial and mammalian cells [49]. A D-glucose sensitive probe was

Table 1 Polymeric matrices, transduction method, detection method and analytes for detection systems based on interactions of boronic acid

\begin{tabular}{|c|c|c|c|c|c|}
\hline $\begin{array}{l}\text { Type of } \\
\text { matrix }\end{array}$ & Transduction & Detection method & Matrix material & Analyte & Ref. \\
\hline \multirow[t]{10}{*}{ Polymer } & \multirow[t]{5}{*}{ Optical } & Near-infrared & Polyacrylamide & Glucose & [47] \\
\hline & & Fluorescence & Polyacrylamide & Glucose, Oxygen & [49] \\
\hline & & Fluorescence & Polyacrylamide & Glucose & [51] \\
\hline & & Fluorescence & Sepharose & $\begin{array}{l}\text { Glucose, } \\
\text { Fructose }\end{array}$ & [54] \\
\hline & & Fluorescence & Polyacrylate & $\begin{array}{l}\text { Glucose as } \\
\text { effector }\end{array}$ & [52] \\
\hline & \multirow[t]{4}{*}{ Electrochemical } & Potentiometry, Impedance & PVC membrane & $\mathrm{NaF}$ & [58] \\
\hline & & $\begin{array}{l}\text { Potentiometry Sequential } \\
\text { Injecion Analysis }\end{array}$ & PVC membrane & Amino acids & [59] \\
\hline & & Potentiometry & $\begin{array}{l}\text { electrochemically copolymerised phenylboronic acid/ } \\
\text { thiophene derivatives }\end{array}$ & Glucose & {$[57]$} \\
\hline & & Impedance & Electropolymerised 3-aminophenylboronic acid & Dopamine & [56] \\
\hline & $\begin{array}{l}\text { Acoustic/ } \\
\text { mechanic }\end{array}$ & Viscometry & Polyacrylamide & Glucose & [53] \\
\hline \multirow[t]{4}{*}{ MIP } & \multirow[t]{2}{*}{ Electrochemical } & Voltammetry & Polyacrylamide & Dopamine & [60] \\
\hline & & Voltammetry & Poly(aniline-co-anthranilic acid) & Dopamine & [61] \\
\hline & Optical & Fluorescence & Polymethacrylate/colloidosomes & Isoproterenol & [62] \\
\hline & Acoustic & Quartz crystal microbalance & Polyacrylate & Mannose, $\lg \mathrm{M}$ & [63] \\
\hline \multirow{2}{*}{$\begin{array}{l}\text { Photonic } \\
\text { crystal }\end{array}$} & \multirow[t]{2}{*}{ Optical } & Diffraction & Poly(acrylamide-co-methacrylate) & Glucose & [64] \\
\hline & & Diffraction & Polystyrene & Fructose & [48] \\
\hline Vesicles & Optical & Fluorescence & N-Alkyl-3-boronopyridinium surfactants & Monosaccharides & [55] \\
\hline
\end{tabular}


based on the Shinkai bis-boronic acid derivative [50] and for oxygen sensing a modified perfluoro-platinum porphyrin was used.

Changes of the gel diameter (swelling, shrinking) can be used for detection and also for therapeutic purposes. An acrylamide gel containing boronic acid and low-cost fluorescent dye, Bordeaux $\mathrm{R}$ was used for a detection of glucose. The Bordeaux $\mathrm{R}$ interacts with amide groups of the gel and causes the gel to shrink. On exposure of the gel to D-glucose the polymer network swells and distorts the $\pi-\pi$ stacking in the assemblies of dye molecules, thus modulating the fluorescence intensity of the dye molecules embedded in the gel [51]. The therapeutic application can be exemplified via a polyacrylicboronic acid gel which shrinks or swells depending on the D-glucose concentration (Figure 12). Such systems could be used for the D-glucose controlled release of insulin [52].

The viscosity of a polyacrylamide scaffold was used for analytical purposes. Changes in viscosity due to fluctuations in D-glucose concentrations were detected using microelectromechanical system (MEMS) [53].

A sepharose gel with appended boronic acid functionality (click chemistry) exhibited dose-dependent fluorescence intensity upon binding with D-glucose and D-fructose [54]. The fluorophore ARS was used to characterise the binding properties of amphiphilic boronic acid vesicles in a detection system for diols [55].

Electropolymerisation is a technique for the tightly controlled and defined preparation of polymeric structures. Electropolymerised 3-aminophenylboronic acid was used for the impedimetric detection of dopamine [56] and a co-polymer of phenylboronic acid with thiophene was used for the potentiometric detection of $\mathrm{D}$ glucose [57].

Furthermore, a boronic acid derivative was incorporated into a PVC membrane and integrated into an electrode that was employed for potentiometric detection of sodium and impedimetric detection of fluoride ions. Fluoride ions interacting with the boron atom served as an effector [58]. The so-called electronic tongue combining a potentiometric sensor array with sequential injection analysis (SIA) was employed for the determination of four different amino acids - phenylalanine, tyrosine, ornithine and glutamic acid. The individual sensors were based on polymeric membranes (plasticised PVC) containing 4-octyloxyphenylboronic acid as an ionophore [59].

\section{Molecular imprinted polymers (MIP)}

Many different materials and methods have been used for the preparation of diol sensors based on molecularly imprinted polymers. The boronic acid unit has specific receptor abilities suitable for MIP technology.

A MIP electropolymerised onto the surface of an electrode was used for the quantification of dopamine [60], imprinted poly(aniline-co-anthranilic acid) as the supporting material together with phenylboronic acid was able to detect dopamine in human plasma [61]. Molecularly imprinted nanoparticles - colloidosomes provided with boronic acid were used for quantification of the $\beta$-adrenergic receptor agonist, isoproterenol. Colloisodomes were synthesised by means of click chemistry [62]. Acrylate-based MIP immobilised on a QCM sensor was used for the selective recognition of immunoglobulin M (IgM) and mannose over fructose [63]. MIP technology was also used for preparation of a photonic crystal technology with sensitivity towards glucose [64].

\section{Electrophoresis}

Boronic acid is well suited for affinity based detection and separation techniques such as electrophoresis (Figure 13). Capillary electrophoresis was established and validated to probe the interactions between boronic acids and cis-diolcontaining biomolecules. Interaction of 14 different boronic acids and 5 typical monosaccharides was comprehensively studied and kinetic data was obtained, however,

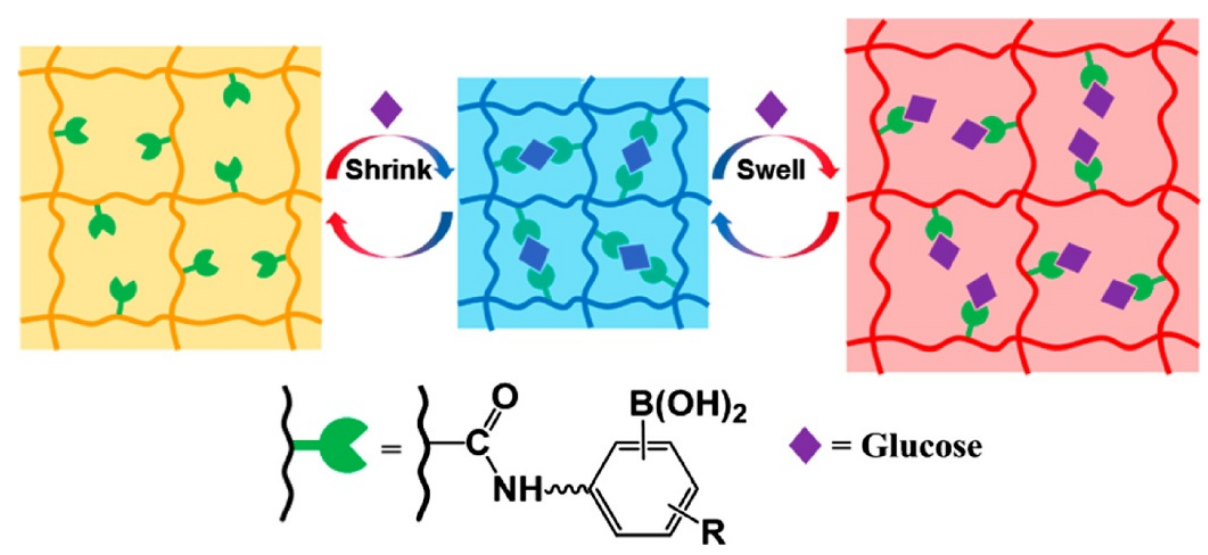

Figure 12 Concentration dependent shrinking or swelling of the polymer. (Adapted from ref. [52]). 


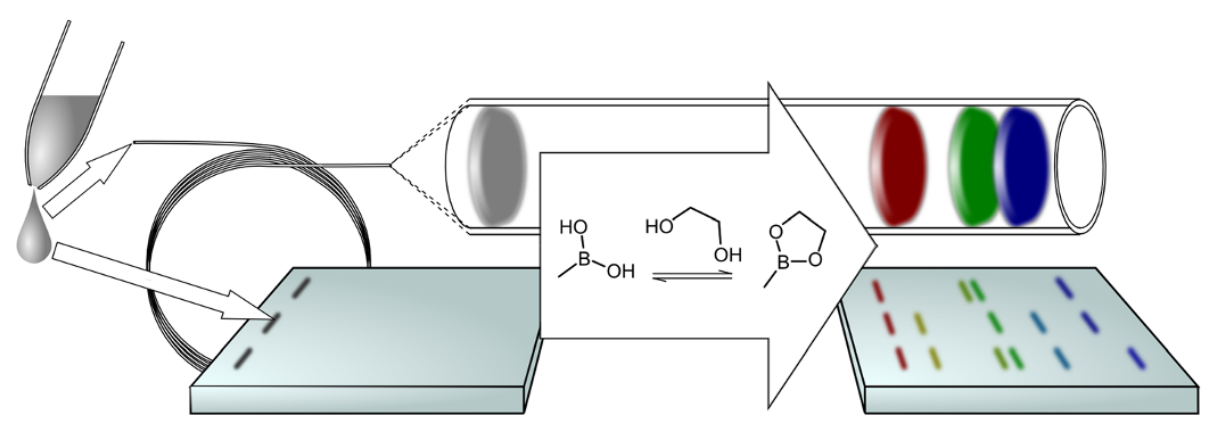

Figure 13 Utilisation of specific boronic acid-diol interactions for a capillary or gel electrophoresis.

deeper discussion concerning the nature of the interactions is lacking [65]. Furthermore electrophoresis combined with boronic acid derivatives seems promising for the analysis of monosaccharides [66], glycoproteins - detection of glycated haemoglobin [67] and as a powerful proteomic tool with the ability to identify potential biomarkers for age-related diseases [68].

\section{Micro and nanoparticles}

The unique abilities of micro- and especially nanoparticles can be enhanced by incorporation of boronic acids to the outer surface (Figure 14). For example, the abilities to prepare diverse sensor materials by the modification of carbon nanotubes were reviewed [11]. An approach combining boronic acid and single-walled carbon nanotubes (SWNT) resulted in near-infrared (NIR) optical glucose sensors, that could be used for long-term in vivo continuous glucose monitoring. The modulation of SWNT fluorescence upon glucose binding and potential in vivo applications for clinical use was discussed [11].

Carbon is a popular building material used in many "nanoapplicaitons". A transistor made of carbon nanotubes functionalised with pyrene-1-boronic acid was sensitive to concentrations of D-glucose in dilute solution at the $\mathrm{nM}$ level [69]. D-Glucose, D-fructose and D-mannose were determined in fruit juices using glassy carbon electrodes modified with graphene oxide and 4-aminophenylboronic acid [70]. The interaction of boronic acid modified water-insoluble carbon nanoparticles with the aromatic diol caffeic acid was measured using a pyrolytic graphite electrode, the interactions could be described using Langmuirian binding kinetics [71]. Quantum dots (QD) are another promising material for analytical purposes, especially for clinical applications [72]. 3-aminophenylboronic acid functionalised graphene quantum dots together with microdialysis were used for the selective detection of D-glucose in rat striatum. The fluorescence of the QD was observed upon the addition of saccharides.

Gold nanoparticles are the subject of several interesting works from 2013. The combination of mercaptophenylboronic acid, gold nanoparticles, graphene and enzyme glucose oxidase resulted in a material able to detect glucose [73]. The same analyte was detected using a system consisting of gold nanoparticles functionalised with calix [4] arene/phenylboronic acid [74]. Gold nanoparticles modified with 4-mercaptophenylboronic acid were used to detect tyrosinase activity. The system was used to quantify surface bound catechol which was produced by enzymatic oxidation of phenol initially present in the system [75]. In another study investigating potential cancer marker, microRNA was captured by a DNA probe on the electrode
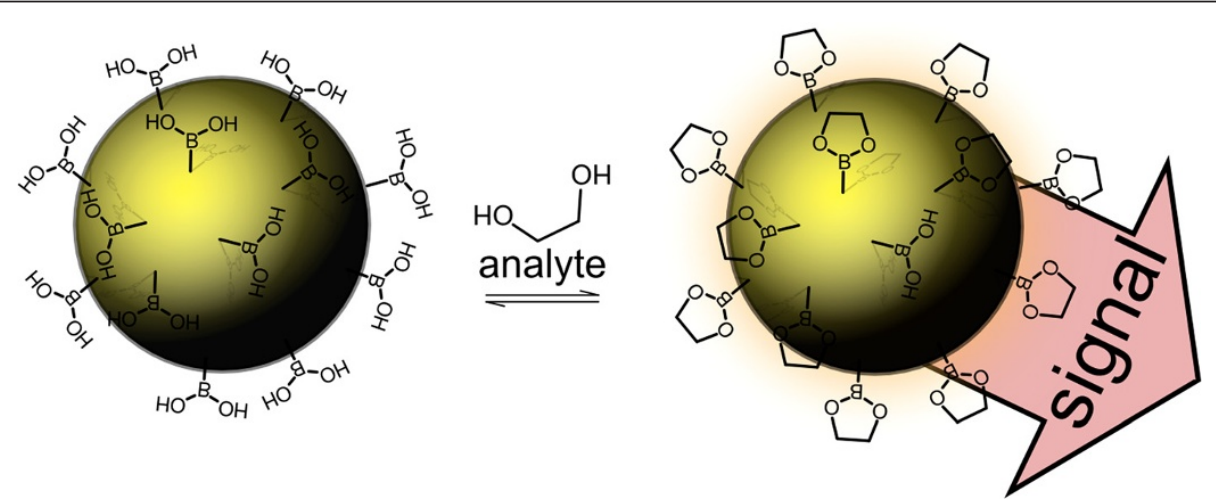

Figure 14 Selective detection of diols using nanoparticles modified with boronic acids. 


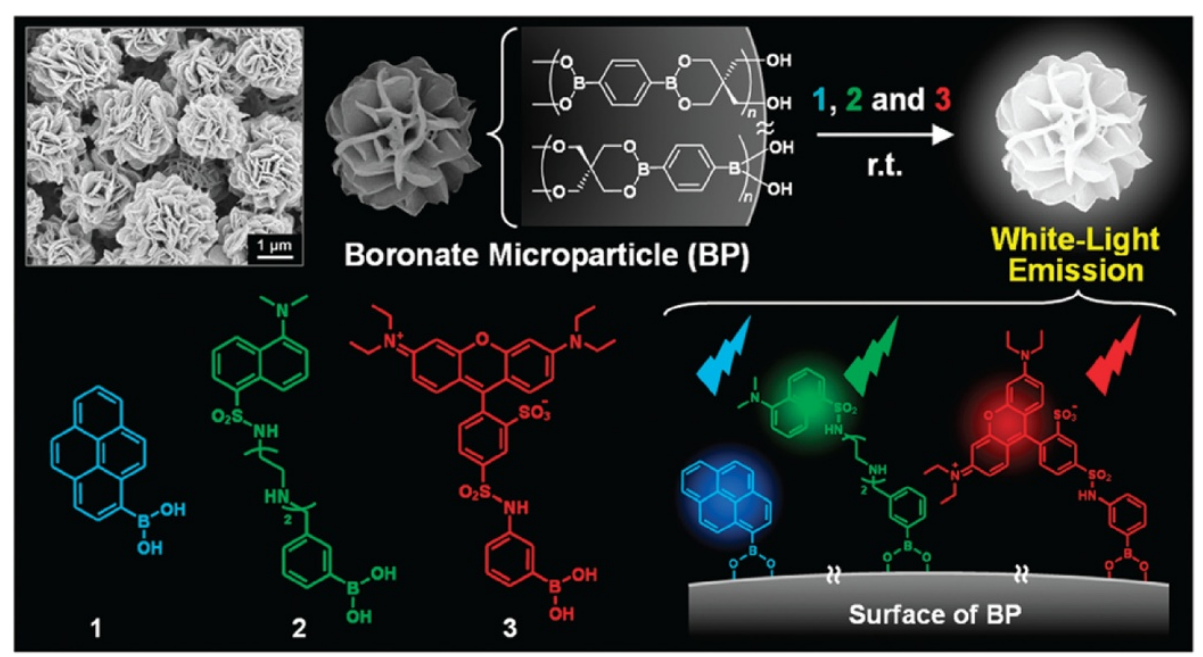

Figure 15 Preparation of water-dispersible white-light emitting boronate microparticles together with the structure of reporter dyes employed. (Adapted from ref. [77]).

surface. 4-mercaptophenylboronic acid appended gold nanoparticles and catechol functionalised gold nanoparticles (as an electrochemical label) were used in this system [76].

A sophisticated and elegant system using three different fluorophores to produce white light was developed (Figure 15). Three flourophores were immobilised by means of boronic acid/diol interactions. After interaction with different concentrations of analyte, $\mathrm{Cu}^{2+}$ ions, the emission was quenched thus altering the colour [77].

\section{Detection of reactive oxygen species (ROS)}

A relatively recent sensing area using boronic acids are chemosensors for the detection of reactive oxygen species (ROS) (Figure 16). ROS play an important role in cellular signalling, immune response and take part in many pathological processes. Oxidative cellular damage is also, related with illnesses such as cancer and Alzheimer's disease. A recently reported sensor molecule detects ROS via the cleavage of a boronate group from an ester of a fluorogenic boronic acid (Figure 17) [78].

Peroxynitrate and hypochlorite anions are also important members of the ROS family. Peroxynitrate was detected using a sensor combining boronic acid and luminescent luciferin [79]. Peroxynitrate was also, detected using the genetically encoded fluorescent protein with appended boronic acid [80]. While, a water soluble styrylquinolinium boronic acid (5) was used for the selective sensing of hypochlorite anion [81].

\section{Electrochemical detection}

Electrochemical methods (Figure 18) are fewer in comparison to optical methods, however, they are highly desirable for all surface confined sensing applications. For example, heterogeneous applications which take place at<smiles>OB(O)c1cc2ccc3cccc4ccc(c1)c2c34</smiles>
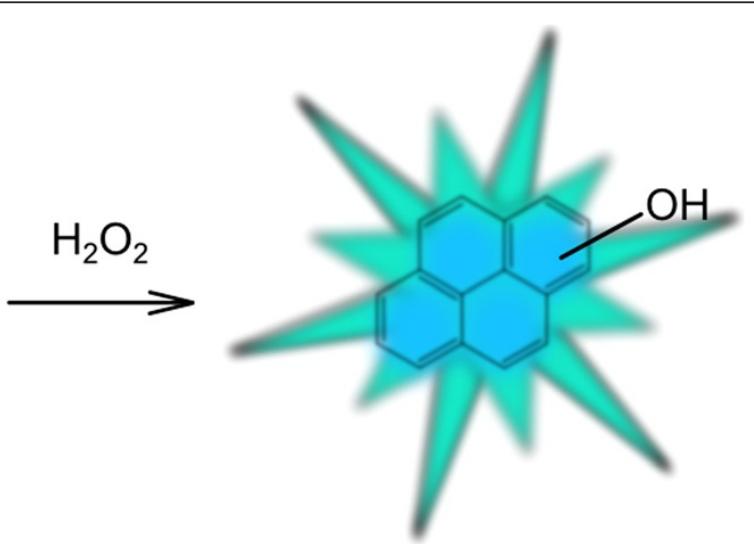

Figure 16 Boronic acid-based molecular sensors for the homogeneous optical detection of reactive oxygen species. 


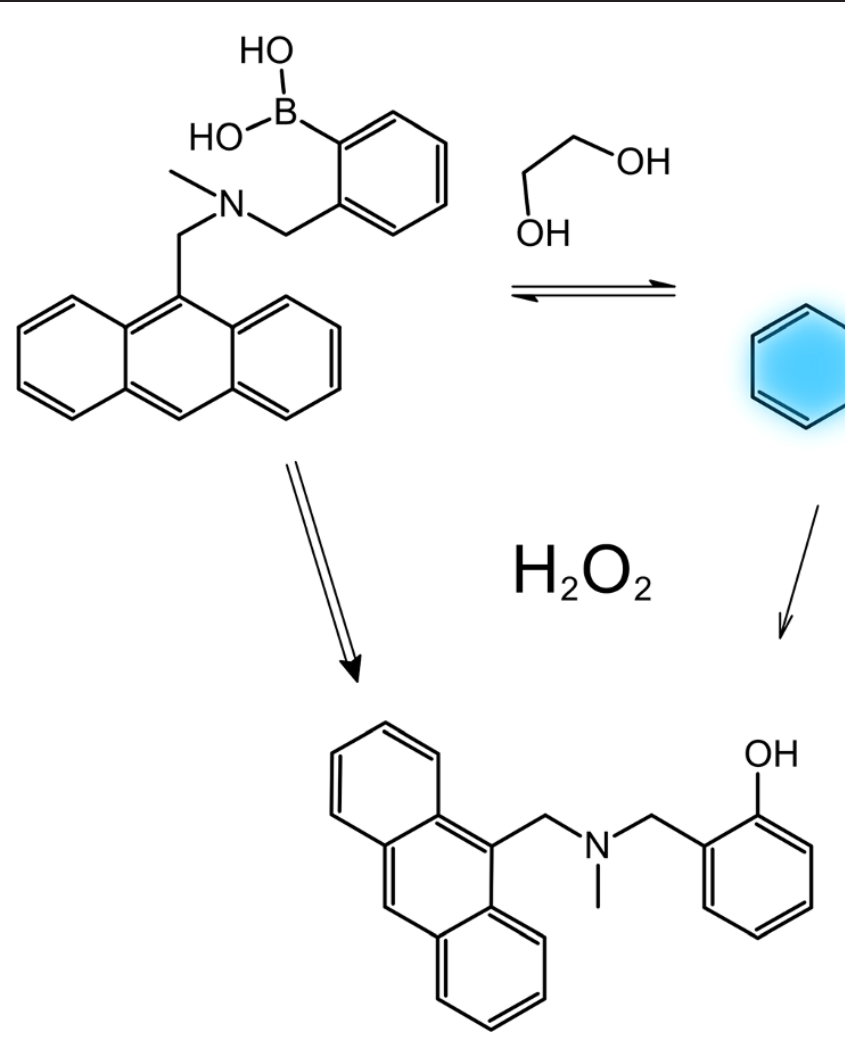

Figure 17 The cleavage of the boronate group from fluorogenic derivative used for the detection of reactive oxygen species $\left(\mathrm{H}_{2} \mathrm{O}_{2}\right)$ [78].

the interphase of solution and electrode modified with boronic acids. In fact the majority of the previously discussed surface related detection systems use electrochemical methods for the transduction of the out-put signal. Electrochemical impedance spectroscopy was used for the sensing at a surface [41-43] and also in polymers [56,58]. Changes in another electrochemical property, the surface potential can also be followed using classical potentiometry $[57,58]$ and using this technique makes the construction of an electronic tongue feasible [59].

As previously discussed many heterogeneous sensing applications utilise field effect transistors with the modulation of their electronic characteristics [44-46,69]. Importantly, the heterogeneous process of interaction of surface-bound boronic acid with diol can be improved by inclusion of nanoparticles [69-71,75,76].

Although electrochemical methods are from their very nature heterogeneous, homogeneous processes can also be probed using these techniques. This type of electrochemical detection can be based on either electrochemically active derivatives of boronic acid evolved from e.g. ferrocene [82] and other typical electrochemical labels or the electroactivity of the diol molecule. Voltammetric techniques, e.g. cyclic and differential pulse voltammetry (CV and DPV) with their

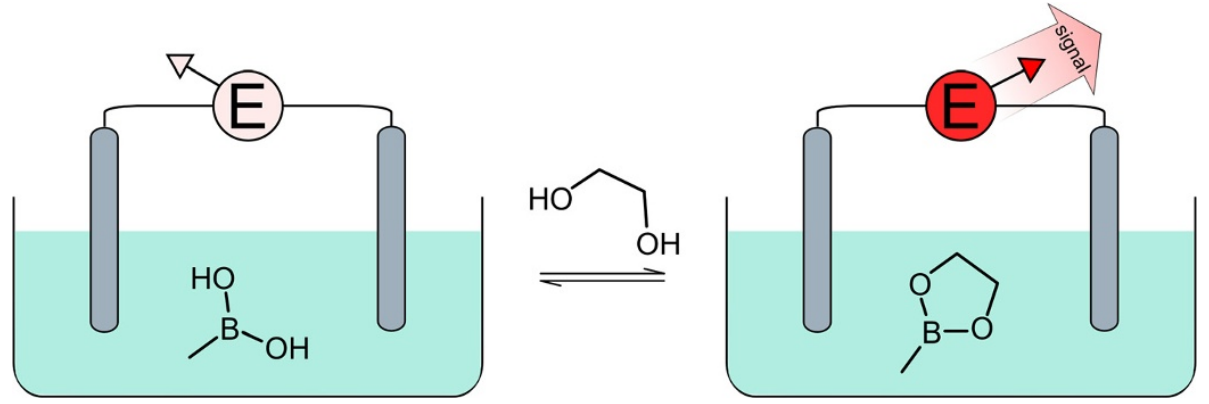

Figure 18 Electrochemical detection based on the boronic acid-diol interaction. 


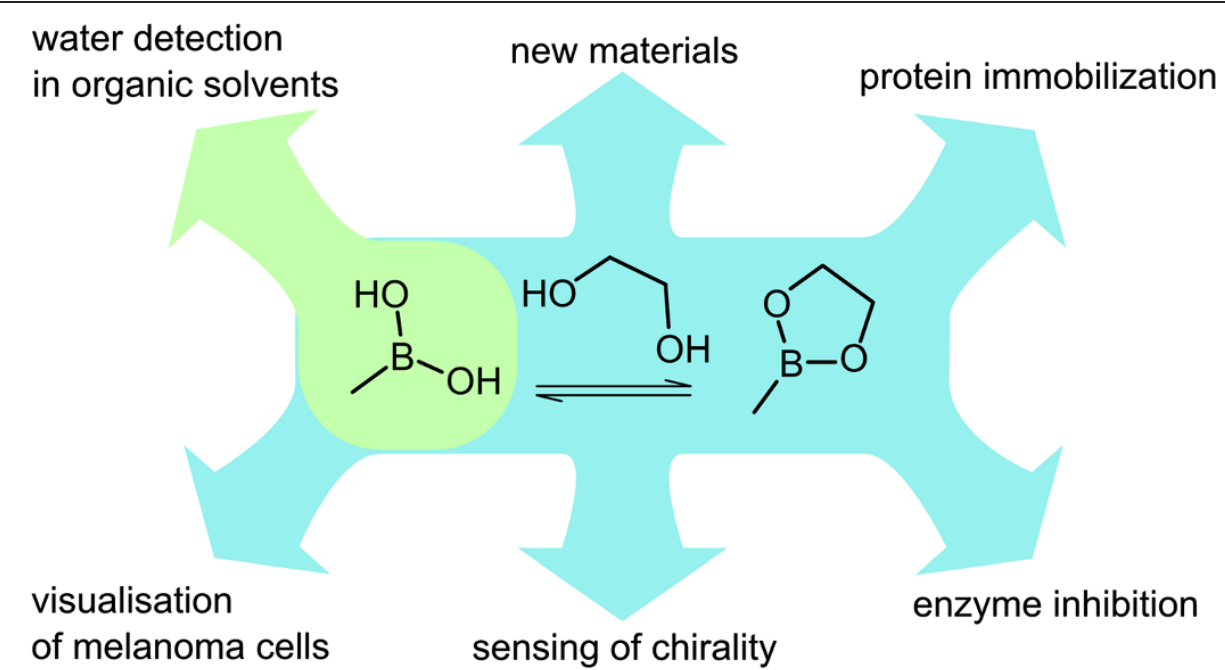

Figure 19 The many diverse and potential applications for boronic acid groups.

versatility are the method of choice. DPV performed on glassy carbon electrodes with graphene-4-aminophenyl boronic acid have been used for the detection of D-fructose, D-glucose and D-mannose [70]. Both CV and DPV were used for the detection of molecules with biological relevance - dopamine [60,61], caffeic acid [71], tyrosinase [75] and microRNA $[76,83]$. Also, the Wang ARS displacement assay [17] was modified and used for the electrochemical detection of saccharides [84]. In this case dopamine was employed as the reporter molecule which is being displaced in the course of measurement.

\section{Other systems and applications}

Boronic acids play a crucial role not only in organic synthesis, but they are vital in many sensor applications and also find use in a range of therapeutic applications (Figure 19). Therefore, it is not surprising then that the well described behaviour of boronic acid is still at the fore-front of research by the scientific community. In order to understand this vital interaction better, the behaviour of arylboronic acids was systematically investigated using ESI-MS [85]. A detailed computational investigation of the ability of boronic acids to bind saccharides was carried out [86]. The important role of the interaction between an ortho-aminomethyl functionality and boron was studied [87]. Furthermore this functionality was utilised for quantification of trace amount of water in organic solvents (Figure 20). Fluorescence from the anthracene-boronic acid esters was used to measure the amount of water present [88].

Self-assembled microspheres were prepared from benzene-1,4-diboronic acid and pentaerythritol [77]. Since polyols and especially saccharides are abundant structures in biological systems, they can be employed with boronic acids in many biocompatible applications. Chaperonin-based boronic acid embedded nanocarriers displayed selective guest release on changes in the concentration of ATP [89]. Boronic acid modified nanocarriers lead to the enhanced uptake by human epithelial carcinoma<smiles>CN(Cc1ccccc1B1OC(C)(C)C(C)(C)O1)Cc1c2ccccc2cc2cc(O)ccc12</smiles>

Figure 20 Fluorescence detection of water in organic solvents [88]. 
cells. Therefore, the construction of biomolecular machinery with the aim of localised delivery and release of therapeutic agents was suggested.

Boronic acids were used for the direct immobilisation of proteins by the interaction with the glycosylated part of the protein structure [90-92] or by means of immobilisation of their particular coenzymes $[93,94]$ for their detection or for the detection of other analytes. Boronic acid derivatives were employed for the visualisation of tumour cells (Figure 21). Interaction of boronic acid-magnetic resonance imaging (MRI) probe (Gadolinium based chelate) with overexpressed sialic acid on the surface of cells was used to locate melanoma cells [95].

Boronic acids have also been used to investigate the interactions and functions of proteins. The rationally designed boronic acid derivative (1-tridecylboronic acid) inhibited siderophore biosynthetic enzymes, and it was proposed as a possible treatment to control $\mathrm{P}$. aeruginosa infections. It is assumed that the derivative mimics an important reaction transition state [96].

A sophisticated ensemble of 2-formylphenylboronic acid and enantiopure BINOL for the detection of enantiomeric purity of chiral hydroxylamines was reported. The resulting mixture of diastereomeric nitrono-boronate esters reflects the enantiopurity of the parent hydroxylamine [97]. Finally, a sensor for cationic surfactants based on polydiacetylene oxyphenylboronic acids was developed and tested [98].

\section{Conclusions}

The utilisation of boronic acid in many diverse areas of chemistry and biology were reviewed. One of the most common applications of boronic acids (BAs) is the detection of diols and anions. Some interesting examples of specific molecular receptors, using novel sensing methods were reported (optical or electrochemical). In particular, sensing applications were developed from the direct immobilisation of the boronic acid based receptors to a surface or as part of a polymeric matrix. Moreover, suitably modified polymeric matrices were used for functional materials, for example the controlled release of insulin. The properties of BAs can be enhanced or modified by anchoring them to a surface of micro or nanoparticles. There is a growing interest the use of BAs in the sensing and labelling of biologically important molecules such as proteins, and the detection of reactive oxygen species (ROS).

From this review it is hoped that the reader will discover that "Boronic acids" have many uses including synthetic chemistry (not included in this review), biological labelling, therapeutic applications (medicinal treatment), protein manipulation (immobilisation), affinity separation and much more. It is important to note that the area of BA research is still open for the development of new ideas, including the development of new detection methods and novel functional materials, towards the development of systems with impact for real world applications.

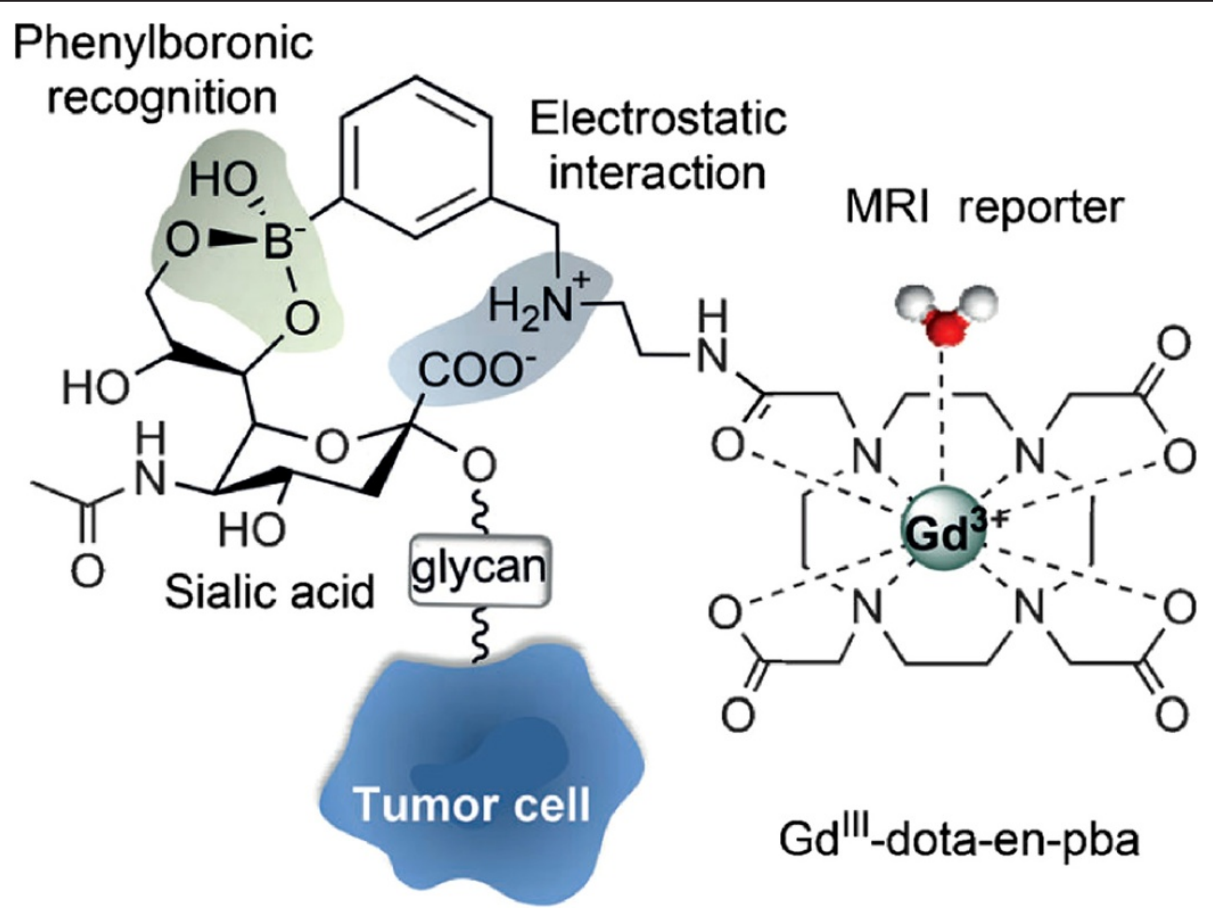

Figure 21 Magnetic resonance imaging (MRI) of tumour cells. The over-expressed sialic acid on the cell membrane is recognised by the boronic acid-based MRI agent. (Adapted from ref. [95]). 


\section{Abbreviations}

ARS: Alizarin Red S; BINOL: 1,1'-bi-2-naphthol; BODIPY: 4,4-difluoro-4-bora3a,4a-diaza-s-indacene; CV: Cyclic voltammetry; DMSO: Dimethyl sulfoxide; DOPA: 3,4-dihydroxyphenylalanine; DOPAC: 3,4-dihydroxyphenylacetic acid; DPV: Differential voltammetry; ESI-MS: Electrospray ionisation - mass spectroscopy; FET: Field effect transistor; FRET: Förster resonance energy transfer; MEMS: Microelectromechanical system; MIP: Molecular imprinted polymers; MRI: Magnetic resonance imaging; NIR: Near-infrared; NMR: Nuclear magnetic resonance; PVC: Polyvinylchloride; ROS: Reactive oxygen species; SERS: Surface enhanced Raman spectroscopy; SPR: Surface plasmon resonance; SWNT: Single-walled carbon nanotubes; QCM: Quartz crystal microbalance; QD: Quantum dots.

\section{Competing interests}

The authors declare that they have no competing interests.

\section{Authors' contributions}

$\mathrm{KL}$ collected and handled the references, designed and drafted the manuscript. PS helped to write the manuscript. TDJ conceived the concept of the review, and helped with its design and coordination and helped write the manuscript. All authors read and approved the final manuscript.

\section{Acknowledgements}

TDJ and $\mathrm{KL}$ are grateful for financial support from the University of Bath, from CEITEC facility (CZ.1.05/1.1.00/02.0068) and the European Social Fund and the State Budget of the Czech Republic (project No. CZ.1.07/2.3.00/ 20.0042) are also acknowledged.

\section{Author details}

'CEITEC, Masaryk University, Kamenice 5, 62500 Brno, Czech Republic. 2Department of Chemistry, University of Bath, Claverton Down, Bath BA2 7AY, UK. ${ }^{3}$ Department of Biochemistry, Faculty of Science, Masaryk University, Kamenice 5, 62500 Brno, Czech Republic

Received: 18 June 2014 Accepted: 6 October 2014

Published online: 18 October 2014

\section{References}

1. Blangetti $M$, Rosso $H$, Prandi C, Deagostino A, Venturello P: Suzuki-Miyaura cross-coupling in acylation reactions. Scope and recent developments. Molecules 2013, 18(1):1188-1213.

2. Kotha S, Lahiri K, Kashinath D: Recent applications of the Suzuki-Miyaura cross-coupling reaction in organic synthesis. Tetrahedron 2002, 58:9633-9695.

3. Qiao JX, Lam PYS: Copper-promoted Carbon-Heteroatom bond crosscoupling with boronic acids and derivatives. Synthesis 2011, 6:829-856.

4. Bull SD, Davidson MG, Van den Elsen JMH, Fossey JS, Jenkins ATA, Jiang YB, Kubo Y, Marken F, Sakurai K, Zhao J, James TD: Exploiting the reversible covalent bonding of boronic acids: recognition, sensing, and assembly. Acc Chem Res 2013, 46(2):312-326.

5. Wu X, Li Z, Chen XX, Fossey JS, James TD, Jiang YB: Selective sensing of saccharides using simple boronic acids and their aggregates. Chem Soc Rev 2013, 42(20):8032-8048

6. Whyte G, Vilar R, Woscholski R: Molecular recognition with boronic acids —applications in chemical biology. J Chem Biol 2013, 6(4):161-174.

7. McClary CA, Taylor MS: Applications of organoboron compounds in carbohydrate chemistry and glycobiology: analysis, separation, protection, and activation. Carbohyd Res 2013, 381:112-122.

8. Wang XJ, Xia N, Liu L: Boronic acid-based approach for separation and immobilization of glycoproteins and its application in sensing. Int J Mol Sci 2013, 14(10):20890-20912.

9. Guan Y, Zhang Y: Boronic acid-containing hydrogels: synthesis and their applications. Chem Soc Rev 2013, 42(20):8106-8121.

10. Hansen J, Christensen J: Recent advances in fluorescent arylboronic acids for glucose sensing. Biosensors 2013, 3(4):400-418.

11. Yum K, McNicholas TP, Mu B, Strano MS: Single-walled carbon nanotube-based near-infrared optical glucose sensors toward in vivo continuous glucose monitoring. J Diabetes Sci Technol 2013, 7(1):72-87.

12. Liu L, Xia N, Xing Y, Deng DH: Boronic acid-based electrochemical sensors for detection of biomolecules. Int J Electrochem Sc 2013, 8(9):11161-11174.
13. Heo YJ, Takeuchi S: Towards smart tattoos: implantable biosensors for continuous glucose monitoring. Adv Healthc Mater 2013, 2(1):43-56.

14. Tohda K: Development of optical sugar sensors as implantable devices for interstitial glucose monitoring. Bunseki Kagaku 2013, 62(10):903-914.

15. Tharmaraj $\vee$, Pitchumani K: D-Glucose sensing by (E)-(4-((pyren-1ylmethylene)amino)phenyl) boronic acid via a photoinduced electron transfer (PET) mechanism. Rsc Adv 2013, 3(29):11566-11570.

16. Neupane LN, Lohani CR, Kim J, Lee K-H: A dual role of phenylboronic acid as a receptor for carbohydrates as well as a quencher for neighboring pyrene fluorophore. Tetrahedron 2013, 69(52):11057-11063.

17. Springsteen G, Wang B: Alizarin Red S. as a general optical reporter for studying the binding of boronic acids with carbohydrates. Chem Commun 2001, 17:1608-1609.

18. Wang ZJ, Lei HY, Feng LH: A facile channel for D-glucose detection in aqueous solution. Spectrochim Acta A 2013, 114:293-297.

19. Huang YJ, Ouyang WJ, Wu X, Li Z, Fossey JS, James TD, Jiang YB: Glucose sensing via aggregation and the use of "Knock-Out" binding to improve selectivity. J Am Chem Soc 2013, 135(5):1700-1703.

20. Teichert JF, Mazunin D, Bode JW: Chemical sensing of polyols with shapeshifting boronic acids as a self-contained sensor array. J Am Chem Soc 2013, 135(30):11314-11321.

21. Bai HY, Sun Q, Tian HY, Qian JH, Zhang LY, Zhang WB: A long-wavelength fluorescent probe for saccharides based on boronic-acid receptor. Chinese J Chem 2013, 31(8):1095-1101.

22. Amin R, Elfeky SA: Fluorescent sensor for bacterial recognition. Spectrochim Acta A 2013, 108:338-341.

23. Hansen JS, Ficker M, Petersen JF, Christensen JB, Hoeg-Jensen T: Ortho-substituted fluorescent aryl monoboronic acid displays physiological binding of D-glucose. Tetrahedron Lett 2013, 54(14):1849-1852.

24. Iwami Y, Yamamoto H, Kanekiyo Y: Multicolor saccharide-analysis sensor arrays based on boronic acid-containing thin films combined with various anionic dyes. Chem Lett 2013, 42(10):1214-1216.

25. Karakus E, Ucuncu M, Eanes RC, Emrullahoglu M: The utilization of $\mathrm{pH}$ sensitive spirocyclic rhodamine dyes for monitoring D-fructose consumption during a fermentation process. New J Chem 2013, 37(9):2632-2635.

26. Xu XD, Cheng H, Chen WH, Cheng SX, Zhuo RX, Zhang XZ: In situ recognition of cell-surface glycans and targeted imaging of cancer cells. Sci Rep-Uk 2013, 3:2679(1-8).

27. Chu Y, Wang DZ, Wang K, Liu ZR, Weston B, Wang BH: Fluorescent conjugate of sLe(x)-selective bisboronic acid for imaging application. Bioorg Med Chem Lett 2013, 23(23):6307-6309.

28. Chaicham A, Sahasithiwat S, Tuntulani T, Tomapatanaget B: Highly effective discrimination of catecholamine derivatives via FRET-on/off processes induced by the intermolecular assembly with two fluorescence sensors. Chem Commun 2013, 49(81):9287-9289.

29. Jun EJ, Liu H, Choi JY, Lee JY, Yoon J: New fluorescent receptor composed of two imidazoliums, two pyrenes and a boronic acid for the recognition of DOPAC. Sensor Actuat B-Chem 2013, 176:611-617.

30. Ptak T, Młynarz P, Dobosz A, Rydzewska A, Prokopowicz M: Potentiometric and NMR complexation studies of phenylboronic acid PBA and its aminophosphonate analog with selected catecholamines. J Mol Struct 2013, 1040:59-64.

31. Jun EJ, Xu ZC, Lee $M$, Yoon J: A ratiometric fluorescent probe for fluoride ions with a tridentate receptor of boronic acid and imidazolium. Tetrahedron Lett 2013, 54(22):2755-2758.

32. Nishimura T, Xu SY, Jiang YB, Fossey JS, Sakurai K, Bull SD, James TD: A simple visual sensor with the potential for determining the concentration of fluoride in water at environmentally significant levels. Chem Commun 2013, 49(5):478-480.

33. Wang XJ, Feng LH, Zhang LW: Reversible "off-on" fluorescent probe for anions based on a facile two-component ensemble. Dyes Pigments 2013 97(2):318-323.

34. Guan RF, Chen HH, Cao FX, Cao DX, Deng YL: Two fluorescence turn-on chemosensors for cyanide anions based on pyridine cation and the boronic acid moiety. Inorg Chem Commun 2013, 38:112-114.

35. Jose DA, Elstner M, Schiller A: Allosteric indicator displacement enzyme assay for a cyanogenic glycoside. Chem-Eur J 2013, 19(43):14451-14457.

36. Chen SJ, Chang JF, Cheng NJ, Yih JN, Chiu KC: Detection of saccharides with a fluorescent sensing device based on a gold film modified with 
4-mercaptophenylboronic acid monolayer. Proc Spie 2013, 8812:881210-881210-9

37. Diltemiz SE, Ersoz A, Hur D, Kecili R, Say R: 4-Aminophenyl boronic acid modified gold platforms for influenza diagnosis. Mat Sci Eng C-Mater 2013, 33(2):824-830

38. Stephenson-Brown A, Wang HC, labal P, Preece JA, Long YT, Fossey JS, James TD, Mendes PM: Glucose selective surface plasmon resonancebased bis-boronic acid sensor. Analyst 2013,

138(23):7140-7145.

39. Arimori S, Ushiroda S, Peter LM, Jenkins ATA, James TD: A modular electrochemical sensor for saccharides. Chem Commun 2002, 20:2368-2369.

40. Kong KV, Lam ZY, Lau WKO, Leong WK, Oivo M: A transition metal carbonyl probe for use in a highly specific and sensitive sers-based assay for glucose. J Am Chem Soc 2013, 135(48):18028-18031.

41. Wang HC, Zhou H, Chen BQ, Mendes PM, Fossey JS, James TD, Long YT: A bis-boronic acid modified electrode for the sensitive and selective determination of glucose concentrations. Analyst 2013, 138(23):7146-7151.

42. Li CC, Li XX, Luo XW, Qi HL: A novel electrochemical impedance spectroscopic sensor for determination of saccharide using phenylboronic acid as molecular recognition element. Chinese J Anal Chem 2013, 41(10):1537-1542.

43. Hsieh KM, Lan KC, Hu WL, Chen MK, Jang LS, Wang MH: Glycated hemoglobin $(\mathrm{HbA}(1 \mathrm{c}))$ affinity biosensors with ring-shaped interdigital electrodes on impedance measurement. Biosens Bioelectron 2013, 49:450-456.

44. Casalini S, Leonardi F, Cramer T, Biscarini F: Organic field-effect transistor for label-free dopamine sensing. Org Electron 2013, 14(1):156-163.

45. Li BR, Chen CW, Yang WL, Lin TY, Pan CY, Chen YT: Biomolecular recognition with a sensitivity-enhanced nanowire transistor biosensor. Biosens Bioelectron 2013, 45:252-259.

46. Matsumoto A, Matsumoto H, Maeda Y, Miyahara Y: Simple and robust strategy for potentiometric detection of glucose using fluorinated phenylboronic acid self-assembled monolayer. Biochim Biophys Acta Gen Subj 2013, 1830(9):4359-4364

47. Hu Y, Jiang $X$, Zhang L, Fan J, Wu W: Construction of near-infrared photonic crystal glucose-sensing materials for ratiometric sensing of glucose in tears. Biosens Bioelectron 2013, 48:94-99.

48. Ayyub OB, Ibrahim MB, Briber RM, Kofinas P: Self-assembled block copolymer photonic crystal for selective fructose detection. Biosens Bioelectron 2013, 46:124-129.

49. Zhang LQ, Su FY, Buizer S, Lu HG, Gao WM, Tian YQ, Meldrum D: A dual sensor for real-time monitoring of glucose and oxygen. Biomaterials 2013, 34(38):9779-9788.

50. James TD, Sandanayake KRAS, Shinkai S: A glucose-selective molecular fluorescence sensor. Angew Chem Int Edit 1994, 33(21):2207-2209.

51. Li YY, Zhou SQ: A simple method to fabricate fluorescent glucose sensor based on dye-complexed microgels. Sensor Actuat B-Chem 2013, 177:792-799.

52. Zhang CJ, Losego MD, Braun PV: Hydrogel-based glucose sensors: effects of phenylboronic acid chemical structure on response. Chem Mater 2013, 25(15):3239-3250

53. Huang X, Li SQ, Davis E, Leduc C, Ravussin Y, Cai HG, Song B, Li D, Accili D, Leibel R, Wang Q, Lin Q: A MEMS differential viscometric sensor for affinity glucose detection in continuous glucose monitoring. J Micromech Microeng 2013, 23(5):055020(1-10).

54. Uddin KMA, Ye L: Fluorogenic affinity gels constructed from clickable boronic acids. J Appl Polym Sci 2013, 128(3):1527-1533.

55. Savsunenko O, Matondo H, Franceschi-Messant S, Perez E, Popov AF Rico-Lattes I, Lattes A, Karpichev Y: Functionalized vesicles based on amphiphilic boronic acids: a system for recognizing biologically important polyols. Langmuir 2013, 29(10):3207-3213

56. Plesu N, Kellenberger A, Taranu I, Taranu BO, Popa I: Impedimetric detection of dopamine on poly(3-aminophenylboronic acid) modified skeleton nickel electrodes. React Funct Polym 2013, 73(5):772-778.

57. Ciftci $H$, Tamer $U$, Sen Teker M, Pekmez NO: An enzyme free potentiometric detection of glucose based on a conducting polymer poly (3-aminophenyl boronic acid-co-3-octylthiophene). Electrochim Acta 2013, 90:358-365.

58. Wongsan W, Aeungmaitrepirom W, Chailapakul O, Ngeontae W, Tuntulani T: Bifunctional polymeric membrane ion selective electrodes using phenylboronic acid as a precursor of anionic sites and fluoride as an effector: a potentiometric sensor for sodium ion and an impedimetric sensor for fluoride ion. Electrochim Acta 2013, 111:234-241.

59. Janczyk M, Kutyla-Olesiuk A, Ceto X, del Valle M, Ciosek P, Wroblewski W: Resolution of amino acid mixtures by an array of potentiometric sensors based on boronic acid derivative in a SIA flow system. Sensor Actuat B-Chem 2013, 189:179-186.

60. Hong SJ, Lee LYS, So MH, Wong KY: A dopamine electrochemical sensor based on molecularly imprinted poly(acrylamidophenylboronic acid) film. Electroanal 2013, 25(4):1085-1094.

61. Gu L, Jiang XY, Liang Y, Zhou TS, Shi GY: Double recognition of dopamine based on a boronic acid functionalized poly(aniline-co-anthranilic acid)molecularly imprinted polymer composite. Analyst 2013, 138(18):5461-5469.

62. Shen XT, Xu CG, Uddin KMA, Larsson PO, Ye L: Molecular recognition with colloidosomes enabled by imprinted polymer nanoparticles and fluorogenic boronic acid. J Mater Chem B 2013, 1(36):4612-4618.

63. Diltemiz SE, Hur D, Kecili R, Ersoz A, Say R: New synthesis method for 4-MAPBA monomer and using for the recognition of IgM and mannose with MIP-based QCM sensors. Analyst 2013, 138(5):1558-1563.

64. Xue F, Duan TR, Huang SY, Wang QH, Xue M, Meng ZH: A covalently imprinted photonic crystal for glucose sensing. J Nanomater 2013, 2013:530701(1-7)

65. Lu CC, Li HY, Wang HY, Liu Z: Probing the interactions between boronic acids and cis-diol-containing biomolecules by affinity capillary electrophoresis. Anal Chem 2013, 85(4):2361-2369.

66. Yin $X Y$, Dong JY, Wang HY, Li S, Fan LY, Cao CX: A simple chip free-flow electrophoresis for monosaccharide sensing via supermolecule interaction of boronic acid functionalized quencher and fluorescent dye. Electrophoresis 2013, 34(15):2185-2192.

67. Dong JY, Li S, Wang HY, Meng QH, Fan LY, Xie HY, Cao C, Zhang W: Simple boric acid-based fluorescent focusing for sensing of glucose and glycoprotein via multipath moving supramolecular boundary electrophoresis chip. Anal Chem 2013, 85(12):5884-5891.

68. Morais MPP, Marshall D, Flower SE, Caunt CJ, James TD, Williams RJ, Waterfield NR, van den Elsen JMH: Analysis of protein glycation using fluorescent phenylboronate gel electrophoresis. Sci Rep-Uk 2013, 3:1437(1-7).

69. Lerner MB, Kybert N, Mendoza R, Villechenon R, Lopez MAB, Johnson ATC: Scalable, non-invasive glucose sensor based on boronic acid functionalized carbon nanotube transistors. App/ Phys Lett 2013, 102(18):183113(1-4).

70. Wang Q, Kaminska I, Niedziolka-Jonsson J, Opallo M, Li MS, Boukherroub R, Szunerits S: Sensitive sugar detection using 4-aminophenylboronic acid modified graphene. Biosens Bioelectron 2013, 50:331-337.

71. Lawrence K, Nishimura T, Haffenden P, Mitchels JM, Sakurai K, Fossey JS, Bull SD, James TD, Marken F: Pyrene-anchored boronic acid receptors on carbon nanoparticle supports: fluxionality and pore effects. New J Chem 2013, 37(7):1883-1888

72. Qu ZB, Zhou XG, Gu L, Lan RM, Sun DD, Yu DJ, Shi G: Boronic acid functionalized graphene quantum dots as a fluorescent probe for selective and sensitive glucose determination in microdialysate. Chem Commun 2013, 49(84):9830-9832.

73. Gupta VK, Atar N, Yola ML, Eryilmaz M, Torul H, Tamer U, Boyaci $\mathbb{H}_{\text {, }}$ Ustundag Z: A novel glucose biosensor platform based on Ag@AuNPs modified graphene oxide nanocomposite and SERS application. J Colloid Interf Sci 2013, 406:231-237.

74. Pandya A, Sutariya PG, Menon SK: A non enzymatic glucose biosensor based on an ultrasensitive calix[4]arene functionalized boronic acid gold nanoprobe for sensing in human blood serum. Analyst 2013, 138(8):2483-2490

75. Xia N, Zhang LP, Feng QQ, Deng DH, Sun XL, Liu L: Amplified voltammetric detection of tyrosinase and its activity with dopaminegold nanoparticles as redox probes. Int J Electrochem SC 2013, 8(4):5487-5495.

76. Xia N, Zhang LP, Wang GF, Feng QQ, Liu L: Label-free and sensitive strategy for microRNAs detection based on the formation of boronate ester bonds and the dual-amplification of gold nanoparticles. Biosens Bioelectron 2013, 47:461-466.

77. Nishiyabu R, Sugino Y, Kubo Y: White-light emitting boronate microparticles for potential use as reusable bright chemosensors in water. Chem Commun 2013, 49(84):9869-9871. 
78. Sun XL, Xu SY, Flower SE, Fossey JS, Qian XH, James TD: "Integrated" and "insulated" boronate-based fluorescent probes for the detection of hydrogen peroxide. Chem Commun 2013, 49(75):8311-8313.

79. Sieracki NA, Gantner BN, Mao M, Horner JH, Ye RD, Malik AB, Newcomb ME, Bonini MG: Bioluminescent detection of peroxynitrite with a boronic acid-caged luciferin. Free Radical Bio Med 2013, 61:40-50

80. Chen ZJ, Ren W, Wright QE, Ai HW: Genetically encoded fluorescent probe for the selective detection of peroxynitrite. J Am Chem Soc 2013, 135(40):14940-14943.

81. Wang Q, Liu C, Chang JJ, Lu Y, He S, Zhao LC, Zeng XS: Novel water soluble styrylquinolinium boronic acid as a ratiometric reagent for the rapid detection of hypochlorite ion. Dyes Pigments 2013, 99(3):733-739.

82. Lacina K, Skládal P: Ferroceneboronic acid for the electrochemical probing of interactions involving sugars. Electrochim Acta 2011, 56(27):10246-10252.

83. Xia N, Wang XJ, Deng DH, Wang GF, Zhai HY, Li SJ: Label-free electrochemical sensor for MicroRNAs detection with ferroceneboronic acids as redox probes. Int J Electrochem Sc 2013, 8(7):9714-9722.

84. Li J, Sun YQ, Wei YM, Zheng JB: Phenylboronic acid and dopamine as probe set for electrochemical detection of saccharides. Chinese Chem Lett 2013, 24(4):291-294.

85. Wang LF, Dai CF, Burroughs SK, Wang SML, Wang BH: Arylboronic acid chemistry under electrospray conditions. Chem-Eur J 2013, 19(23):7587-7594.

86. Petsalakis ID, Theodorakopoulos G: Boronic acid sensors for saccharides: a theoretical study. Chem Phys Lett 2013, 586:111-115.

87. Collins BE, Metola P, Anslyn EV: On the rate of boronate ester formation in ortho-aminomethyl-functionalised phenyl boronic acids. Supramol Chem 2013, 25(2):79-86.

88. Ooyama Y, Uenaka K, Matsugasako A, Harima Y, Ohshita J: Molecular design and synthesis of fluorescence PET (photo-induced electron transfer) sensors for detection of water in organic solvents. Rsc Adv 2013, 3(45):23255-23263

89. Biswas S, Kinbara K, Niwa T, Taguchi H, Ishii N, Watanabe S, Miyata K, Kataoka K, Aida T: Biomolecular robotics for chemomechanically driven guest delivery fuelled by intracellular ATP. Nat Chem 2013, 5(7):613-620.

90. Kim DM, Shim YB: Disposable amperometric glycated hemoglobin sensor for the finger prick blood test. Anal Chem 2013, 85(13):6536-6543.

91. Huang Y, Wang W, Li Z, Qin X, Bu L, Tang Z, Fu YC, Ma M, Xie Q, Yao S, Hu J: Horseradish peroxidase-catalyzed synthesis of poly(thiophene-3-boronic acid) biocomposites for mono-/bi-enzyme immobilization and amperometric biosensing. Biosens Bioelectron 2013, 44:41-47.

92. Song L, Zhao J, Luan SF, Ma J, Liu JC, Xu XD, Yin J: Fabrication of a detection platform with boronic-acid-containing zwitterionic polymer brush. Acs Appl Mater Inter 2013, 5(24):13207-13215.

93. Abdellaoui S, Corgier BC, Mandon CA, Doumeche B, Marquette CA, Blum LJ: Biomolecules immobilization using the aryl diazonium electrografting. Electroanal 2013, 25(3):671-684

94. Şenel M, Dervisevic M, Çevik E: A novel amperometric glucose biosensor based on reconstitution of glucose oxidase on thiophene-3-boronic acid polymer layer. Curr Appl Phys 2013, 13(7):1199-1204.

95. Crich SG, Alberti D, Szabo I, Aime S, Djanashvili K: MRI visualization of melanoma cells by targeting overexpressed sialic acid with a Gdlll-dota-en-pba imaging reporter. Angew Chem Int Edit 2013, 52(4):1161-1164.

96. Clevenger KD, Wu R, Er JAV, Liu DL, Fast W: Rational design of a transition state analogue with picomolar affinity for pseudomonas aeruginosa PvdQ, a siderophore biosynthetic enzyme. ACS Chem Biol 2013, 8(10):2192-2200

97. Tickell DA, Mahon MF, Bull SD, James TD: A simple protocol for NMR analysis of the enantiomeric purity of chiral hydroxylamines. Org Lett 2013, 15(4):860-863.

98. Lee S, Lee KM, Lee M, Yoon J: Polydiacetylenes bearing boronic acid groups as colorimetric and fluorescence sensors for cationic surfactants. Acs Appl Mater Inter 2013, 5(11):4521-4526.

doi:10.1186/s13065-014-0060-5

Cite this article as: Lacina et al:: Boronic acids for sensing and other applications - a mini-review of papers published in 2013. Chemistry Central Journal 2014 8:60.

\section{Publish with ChemistryCentral and every scientist can read your work free of charge \\ "Open access provides opportunities to our colleagues in other parts of the globe, by allowing anyone to view the content free of charge." W. Jeffery Hurst, The Hershey Company. \\ - available free of charge to the entire scientific community \\ - peer reviewed and published immediately upon acceptance \\ - cited in PubMed and archived on PubMed Central \\ - yours - you keep the copyright \\ Submit your manuscript here: \\ http://www.chemistrycentral.com/manuscript/<smiles>c1ccccc1</smiles> \\ Chemistry Central}

